\title{
Machuca, Paulina, El vino de cocos en la Nueva España. Historia de una transculturación en el siglo XVII, 2018. ISBN: 978-607-544-034-7
}

\author{
Oscar David Rivera Garrido*
}

\begin{abstract}
El vino de cocos fue la primera bebida destilada que irrumpió en el mercado de bebidas alcohólicas de la Nueva España, alrededor del año 1600. Se trató del primer destilado que se produjo, comercializó y consumió en un amplio margen del territorio novohispano, llevándose desde tierra caliente del Pacífico hasta las zonas mineras del septentrión (p. 20)
\end{abstract}

El vino de cocos en la Nueva España, es un libro escrito por Paulina Machuca, doctora en Ciencias Sociales, profesora en El Colegio de Michoacán, miembro del Sistema Nacional de Investigadores y especialista en historia de los intercambios culturales entre México y Filipinas durante los siglos XVI al XIX.

Su libro se encuentra dividido en una breve introducción y tres grandes apartados (De la palma al destilado; Sabedores y aprendices; y Productores, consumidores y castigadores), así como un epílogo titulado El mezcal: ¿heredero del vino de cocos?

En la "Introducción", Machuca aborda la importancia del intercambio cultural gracias a la Nao de China, de la que llegaron el cocotero, arroz, tamarindo y especias, generándose un intercambio de aproximadamente 230 especies de plantas. Además, menciona que la llegada de la palma de coco significó un gran cambio biológico y sociocultural, ya que simultáneamente llegaron los "indios chinos". También se destaca la inserción de los filipinos

* Estudiante de doctorado en Ciencias Sociales, Universidad de Colima, correo electrónico: orivera_garrido@hotmail.com 
en las alcaldías mayores de Colima y de Motines, siendo el eje el desarrollo y declive del vino de coco a lo largo del siglo XVII.

El primer apartado se divide en dos secciones, la primera titulada El árbol de la vida, en la que se destaca el uso de la palma de coco en Asia, así como sus propiedades, particularmente en India y Filipinas, así como la introducción de esta planta a la Nueva España. Machuca aborda la importancia de los cocos para los pueblos originarios de las Bisayas, en Filipinas, cuya mitología considera que el género humano procedía de la unión de dos cocos, también menciona el origen de la palabra coco con registros de los exploradores portugueses como Vasco da Gama, quien registró el término coquos, que de acuerdo al naturalista García da Orta recibía este nombre por contener tres orificios que asemejaban el rostro de un mono u otro animal.

Con relación a la llegada de la palma de coco a América, la autora considera que llegó por la vía polinesia a Centroamérica gracias a que "su semilla tiene la capacidad de diseminarse a través de corrientes marítimas y germinar en el lugar de destino, sin ayuda del hombre” (p. 47). Mientras que por la vía africana llegó a Puerto Rico, Brasil, Santo Domingo, Cuba, Veracruz, Campeche y Yucatán. En el caso de Colima, llegó por el puerto de Salagua el 22 de enero de 1569, proveniente de las Islas Salomón, gracias al navegante leonés Álvaro de Mendaña y Neira, y a partir de 1570 llegaron más cocos desde Filipinas al puerto de Acapulco.

Machuca señala que los colimenses aprovecharon la palma de coco "porque los filipinos lo enseñaron a utilizar en diversos ámbitos de la vida cotidiana, como en la comida, la bebida, la medicina y la arquitectura (...) Las prácticas culinarias asiáticas se hacían presentes en las mesas de los colimenses a principios del siglo XVII" (p. 55 y 57). A continuación, la autora aborda la técnica de elaboración del vino de cocos, desde subir a la palmera para extraer la tuba (savia del coco) hasta su destilación y el inicio de su producción en la Nueva España en 1598 en la provincia de Colima gracias a la mano de obra filipina.

El desarrollo de la producción del vino de cocos se presentó principalmente en el litoral de los actuales estados de Colima, Michoacán y Guerrero, en las entonces alcaldías mayores de Colima y Motines; y las de Zacatula y Acapulco. Las primeras tuvieron la mayor producción de vino de cocos durante la época colonial. Además se promovió el binomio coco-cacao, cultivándose la palma de coco como un árbol de sombra para el cacao en lugar del cacahuanantzin, mientras que en Filipinas se introdujo el cacao, “considerado por muchos filipinos un árbol nativo" (p. 109).

En el segundo apartado, titulado Sabedores y aprendices, se aborda el caso de los "indios chinos" vinateros y el de los indios vinateros y otras 
castas, los primeros son originarios de Asia (Filipinas, China, India, Borneo, Indonesia, Nueva Guinea y Sri Lanka), quienes representan el "fenómeno migratorio indígena transcontinental más importante en el marco del imperio español” (p. 118), ya que se estima que entre 1565 y 1700 ingresaron 7,200 asiáticos, de los cuales 5,000 se quedaron de forma permanente en la Nueva España, principalmente en la Ciudad de México, Colima, Guerrero, Hidalgo, Jalisco, Michoacán, Oaxaca, Puebla, Tabasco, Tlaxcala, Veracruz y Zacatecas.

La autora analiza los mecanismos de inserción laboral de los "indios chinos”, algunos como esclavos y otros libres, principalmente los que participaron en la elaboración de vino de cocos en Colima, algunos de los cuales lograron destacar económicamente dejando testamentos, siendo un punto central la "estrecha y natural vinculación de los inmigrados con su producto nativo, la palma de coco, y este saber tradicional les abrió la puerta para una mejor y más rápida inserción en la sociedad novohispana” (p. 179).

En el caso de los indios vinateros y otras castas, Machuca busca responder cómo afectó la introducción del vino de cocos a los pueblos de indios, destacando que hasta la década de 1630 la producción del aguardiente de palmas era un conocimiento en manos de los "indios chinos", posteriormente "la autorización del vino de cocos incentivó esta actividad y la mano de obra filipina no fue suficiente para abastecer la demanda del aguardiente” (p. 195196), por lo que los indios naturales se convierten en "vinateros" y posiblemente en "maestros de hacer vino".

En el tercer apartado se analiza la producción, consumo y castigo del vino de cocos, abordando las cuatro etapas de la producción del siglo XVII que inicia con la producción del vino de cocos como bebida prohibida en el año 1600 en Colima; su auge después de 1626, año en el que ocurre un fuerte huracán y que se autoriza la producción y comercio como medida de apoyo; el período de 1670 a 1700 de luces y sombras sobre la documentación, sobre todo en Zacatula-Acapulco y de un desplazamiento de las haciendas de palma de beneficio hacia tierra adentro en Colima; y un período de declive de 1700 a 1724 con la prohibición del marqués de Casafuerte.

Aquí se presenta un análisis profundo de la producción anual de vino de cocos, incluyendo los gastos administrativos que éste generaba, el pago de diezmos por este concepto, el ciclo de producción, etcétera. Además, se enfatiza que en Zacatula se siguió reportando una "fuerte presencia de cacao, lo que sugiere que su economía se sirvió de la fabricación de aguardiente como complemento, y no como sustituto del cacao, fenómeno que sí ocurrió en Colima” (p. 235). 
Con relación a las rutas comerciales del vino de cocos, en el caso de Colima abarcó los reinos de la Nueva España, Nueva Galicia y Nueva Vizcaya, "movilizaba la crema y nata del comercio y de los oficiales, sean reales y municipales, de espacios tan dilatados como el occidente, el norte de Nueva España, y tal vez el centro” (p. 286) destacando el comercio hacia Guadalajara, así como las zonas mineras. En el caso del mercado de vino de cocos de Zacatula y Acapulco fue prácticamente en sus alrededores llegando hasta Apatzingán y Valladolid, posiblemente la Ciudad de México, y para los marineros, trabajadores del puerto y mercaderes de Acapulco.

En el análisis de las rutas comerciales se presentan las dificultades del comercio del vino de cocos de Colima en el Obispado de Michoacán y los conflictos por el tema del estanco de la Nueva Galicia, además se empieza a vislumbrar la ventaja del mezcal frente al vino de cocos, ya que "se fabricaba en la Nueva Galicia sin el costo humano (...) Era más fácil transportarlo a Guadalajara y de ahí distribuirlo a las zonas mineras del centro-norte novohispano" (p. 302).

Al finalizar el tercer apartado se desarrolla el tema de la política prohibicionista ante el vino de cocos, teniendo en cuenta que la palma de cocos se había arraigado en la zona de Colima, creando intereses económicos y políticos, por lo que se siguió un doble discurso entre los beneficios y perjuicios de esta bebida alcohólica, severamente criticada por el Virrey Francisco Fernández Duque de Albuquerque (1702-1710) y por el Virrey Marqués de Casafuerte (1724), quien cerró toda posibilidad de reactivar la producción del vino de cocos en el siglo XVIII.

Con relación al epílogo, la autora hace una reflexión sobre el origen del mezcal y la influencia de las técnicas de destilación asiáticas, destacando que "el proceso de elaboración de mezcales, tal como lo conocemos hoy en día, surgió en la época colonial” (p. 358).

Finalmente, este libro de investigación nos permite comprender no solamente la historia del vino de cocos en la Nueva España, sino también el proceso de transculturación en el siglo XVII, gracias a éste se puede entender la época colonial e incluso el México actual, que a veces ha olvidado la influencia filipina y de otros países asiáticos, y sin embargo, está presente en la vida cotidiana, qué mejor ejemplo que Colima, la ciudad de las palmeras. 